\title{
A Comparative Study between Hyperbaric Bupivacaine Alone Versus Fentanyl Versus Nalbuphine in Three Different Doses Intrathecally Adjuvant to Hyperbaric Bupivacaine for Lower Abdominal Surgeries
}

\author{
E.F.Makram , I.S.Abd-Elazeem, M.A.Khashba and L.E.Youssef
}

Anesthesiology and Intensive Care Dept., Faculty of Medicine, Benha Univ., Benha, Egypt

E-Mail:dr_loay1981@yahoo.com

\begin{abstract}
This is a forthcoming randomized control clinical trial.We pointed tocompare between intrathecal hyperbaric bupivacaine alone versusintrathecal hyperbaric bupivacainein formation with one or the other fentanyl; or nalbuphinein 3 distinct portions $(0.2 \mathrm{mg}, 0.4 \mathrm{mg}, 0.8 \mathrm{mg})$. The study was done on 100 grown-up patients planned for elective lower stomach medical procedures under spinal sedation were randomlyallocated to 1 of the accompanying five gatherings to get intrathecally: $15 \mathrm{mg}$ bupivacaine $0.5 \%$ alone (control); bupivacaine $15 \mathrm{mg}$ joined with either $25 \mu \mathrm{g}$ fentanyl; or nalbuphine $0.2,0.4$ and $0.8 \mathrm{mg}$. Segment information, ASA characterization, length of medical procedure, kind of medical procedure, intra-employable Hemodynamic boundaries as the circulatory strain, the pulse and respiratory misery (respiratory rate, oxygen immersion), results as shuddering, sickness and regurgitating, and pruritis, beginning of engine and tactile square, most elevated level of tangible square, span of engine and tangible square, likewise postoperative pulse, non-intrusive pulse, oxygen immersion, torment score visual simple scale, results, term of viable absense of pain, all out number of salvage analgesics in first 24 hours were recorded. The outcome indicated that Both intrathecal nalbuphine and fentayl were viable in giving intra-employable and postusable hemodynamic solidness, improving the time of postoperative complete and compelling absense of pain yet fentanyl was in a way that is better than nalbuphine in spreading beginning of tactile square, However, nalbuphine $0.8 \mathrm{mg}$ is the best in expanding the time of postoperative complete and successful absense of pain, reducing the need of postoperative salvage pain relieving drugs and has better highlights, for example, hostile to pruritic, lesser shuddering, sickness and retching. Our decision is that nalbuphine 0.8 milligram is protected, significant and the best among the gatherings.
\end{abstract}

Keywords: Bupivacaine, Fentanyl, Nalbuphine, Subarachnoid block.

\section{Introduction}

Subarachnoid blockis an all around held onto procedure as it is easy to be performed with fast beginning of activity and significant muscle unwinding however every coin has different sides, it has a more limited span of activity and early emerging postoperative torment so different adjuvant is should have been added and their jobs are being assessed in different examinations [1].

Bupivacaine is normally utilized for subarachnoid block; notwithstanding, intrathecal bupivacaine alone might be inadequate to give total anesthesia [2].

Profoundly lipophilic short-acting narcotics, for example, fentanyl when added to neighborhood sedatives gives thick bar total intra-and postoperative absense of pain without causing hemodynamic unsteadiness and draw out postoperative pain relieving saving thoughtful activity however intrathecal fentanyl is joined with results as pruritis, queasiness/regurgitating and respiratory depression [3].

As of late, nalbuphine has been added as to nearby sedatives, nalbuphine is a narcotic $(\mathrm{mu}) \mu$ receptor rival and (kappa) K-receptor agonist so it can possibly furnish great intra-and postoperative absense of pain with diminished rate and seriousness of $\mu$ receptor results likewise rather than other halfway acting narcotic analgesics, nalbuphine minimally affects breath and low expected maltreatment [4].

\section{Methodology \\ 2.1 Search strategy}

An imminent randomized control clinical preliminary directed in the wake of acquiring institutional moral board of trustees endorsement of the college and getting composed educated assent from patients.

The investigation was done on 100 grown-up patients were arbitrarily assigned similarly to one of the accompanying five gatherings (20 patient in each gathering) to get intrathecally: 15 milligram bupivacaine $0.5 \%$ alone (control); bupivacaine $15 \mathrm{mg}$ joined with either $25 \mu \mathrm{g}$ fentanyl; or nalbuphine 0.2 , 0.4 and $0.8 \mathrm{mg}$.

All patients was assessed by appropriate history taking, clinical assessment, pertinent research center examinations and prepared on the most proficient method to utilize the visual simple scale (VAS) which comprises of $10 \mathrm{~cm}$ line with $0 \mathrm{~cm}=$ no torment and $10 \mathrm{~cm}=$ the most noticeably awful torment.

All patients were approached to quick for at any rate $8 \mathrm{~h}$ before the system and furthermore narcotics and hypnotics was kept away from in pre, intra-and postoperative period.

On appearance of the patient to the usable auditorium an IV line was made sure about with $18 \mathrm{G}$ IV cannula, preloaded with $10 \mathrm{ml} / \mathrm{kg}$ of Ringer's lactate arrangement and appended to multichannel screen to show the pulse (beats/min), constant ECG 
(lead II ), non-invasivearterial circulatory strain $(\mathrm{mmHg})$ and oxygen immersion $(\mathrm{SpO} 2)$.

The patient was then positioned in the sitting situation for lumbar cut utilizing mid line approach under complete aseptic conditions utilizing 25 measure clean expendable spinal needle presented at level L3/4 or L4/5 intervertebral space and subsequent to acquiring a free cerebrospinal liquid (CSF) stream the fitting medication was infused intrathecally as indicated by each gathering gradually. At that point, the patients were put in the prostrate or sidelong situation for medical procedure, Oxygen was given through nasal cannula at the pace of $4 \mathrm{l} / \mathrm{min}$.

Beginning of tangible square was decided by pin prick technique additionally the segmental degree of tactile square to pinprick was assessed reciprocally along the mid-axillary line utilizing a short angled 25 measure hypodermic needle each 2 min until most elevated dermatomal level was reached and engine barricade was decided with adjusted Bromage scale.

Estimations had done incorporate segment information as respect age (a long time), sex, weight $(\mathrm{kg})$, height $(\mathrm{cm})$, ASA arrangement, length of surgery(min), sort of surgery.Intra-usable estimations had done incorporate Haemodynamic boundaries as the circulatory strain (mmhg), the pulse (beats/min) and respiratory discouragement (respiratory rate, oxygen immersion) after the infusion each $5 \mathrm{~min}$ for 20 min then every $10 \mathrm{~min}$ till end of a medical procedure, results as shuddering, queasiness and spewing, and pruritis, the beginning of tactile barricade, total engine bar, most elevated level of tangible bar, term of tactile bar and span of engine bar. Postoperative estimations had done incorporate HR, NIBP, oxygen immersion (SpO2) and torment score visual simple scale (VAS) was recorded at first every one hour for initial 2 hours in the post sedative consideration unit (PACU) at that point recorded at 4h, 6h, 12h and 24h.at patients' ward, results, for example, shuddering, sickness and regurgitating, and pruritis, the term of successful absense of pain (time from the intrathecal infusion to the main salvage pain relieving prerequisite, VAS score >3.5), absolute number of salvage analgesics needed in 24 hours duration postoperative on interest "as it were".

\subsection{Statistical techniques}

Data were taken care of to the PC utilizing IBM SPSS programming bundle variant 20.0.Qualitative information were depicted by utilizing number and percent. Correlation between various gatherings with respect to unmitigated factors was tried by utilizing Chi-square test. Quantitative information were depicted utilizing mean and standard deviation for typically dispersed information while strangely conveyed information was communicated utilizing middle, least and greatest. For regularly conveyed information F-test (ANOVA) can be utilized. Centrality test results are cited as two-followed probabilities. Hugeness of the outcomes was decided at the $5 \%$ level.

\subsection{Inclusions criteria}

100 patients was included in the study are of American Society of Anesthesiologists (ASA) physical status I and II (ASA grade I-II), Both gender, Patients' age ranges between (20-60) years old, Patients undergoing lower abdominal elective surgeries, Patients with body weight $(40-100 \mathrm{~kg})$ and height $>150 \mathrm{~cm}$.

\subsection{Exclusion criteria}

Patients' refusal, Patients who had contraindications to spinal anaesthesia if any, Patients with known hypersensitivity to any of the study drugs, Pregnancy and Emergency operations.

\section{Results}

In this study 130 patients were screened for eligibility, 30 patients of them were excluded from the study, 20 of them didn't fit the inclusion criteria and 10 of them declined to participate Fig (1).

There wasinsignificant statistical difference regarding demographic data as age, weight, height, sex, ASA classification, duration of surgery and type of surgery of enrolled patients presented in Table (1).

There was no significant statistical difference as regard intra-operative and postoperative Haemodynamic parameters as the blood pressure, the heart rate \& respiratory depression (respiratory rate, oxygen saturation).

As presented in Table (2) the incidences of vomiting and nausea and shivering were higher in control and fentanyl groups than nalbuphine groups $(\mathrm{P}<0.05)$ but the incidence of pruritis was higher in fentanyl group than control and nalbuphine groups $(\mathrm{P}$ $<0.05)$.

As described in Table (3) There was a statistical significance as fentanyl group (group $\mathrm{F}$ and group N3) was superior to groups (groups N1 andN2) and control group (group C) in spreading onset of sensory block with $\mathrm{P}$ - value $=0.015$. Group $\mathrm{F}$ show rapid onset sensory blockade than group N3, but this difference was insignificant. Table (3) also shows that on comparison between the five groups regarding highest level of sensory blockade and onset of complete motor blockade it was found both group $\mathrm{F}$ and N3 was fast but this increasing was insignificant $(\mathrm{p}>0.05)$.

The 2 segment regression of sensory blockade and period of motor blockade were more prolonged with adding nalbuphine (0.8mg) (group N3) to intrathecal bupivacaine than addition of fentanyl (25 $\mu$ ) (group F) than the other groups though statistically insignificant, while in the group $\mathrm{C}$ there was a statistical significant decrease than the other groups ( $\mathrm{p}<0.05)$ as described in Table (4).

There was statistical significance as VAS became higher within two hours in group $\mathrm{C}$ post-operative in 
comparison with other 4 groups in which VAS became higher within 4 hours $(\mathrm{P}-$ value $=0.036)$ as in Table (5).

Fig (2) shows the difference in mean period of effective analgesia was statistically significant in the groups when compared with each other, maximal in Group N3 followed by Group F then group N2, N1 and lastly group $\mathrm{C}$ with $\mathrm{P}$ - value $=0.001$.
There was statistical difference as regard Total number of rescue analgesics required in 24 hours period as patients who received intrathecal nalbuphine in groups $\mathrm{N} 1, \mathrm{~N} 2$ and $\mathrm{N} 3$ required significantly lesser number of rescue analgesics than Group C and F. Furthermore, the patients in fentanyl group (group F)required significantly lesser analgesia than the patients in Group $\mathrm{C}$ with $\mathrm{P}$ - value $=0.001$ as in Fig (3).

Table (1) Comparison between the different studied groups regarding demographic data.

\begin{tabular}{|c|c|c|c|c|c|c|c|c|c|c|}
\hline & \multicolumn{2}{|c|}{ Group C } & \multicolumn{2}{|c|}{ Group F } & \multicolumn{2}{|c|}{ Group N1 } & \multicolumn{2}{|c|}{ Group N2 } & \multicolumn{2}{|c|}{ Group N3 } \\
\hline & No & $\%$ & No & $\%$ & No & $\%$ & No & $\%$ & No & $\%$ \\
\hline Sex & 12 & 60 & 11 & 55 & 13 & 65 & 12 & 60 & 12 & 60 \\
\hline Male & 8 & 40 & 9 & 45 & 7 & 35 & 8 & 40 & 8 & 40 \\
\hline \multicolumn{11}{|l|}{ Female } \\
\hline $\mathbf{X}^{2}$ & \multicolumn{10}{|c|}{0.416} \\
\hline $\mathbf{p}$ & \multicolumn{4}{|c|}{4335} & \multicolumn{2}{|c|}{0.98 N.S. } & & & & \\
\hline Age (years) & & & & & & & \multicolumn{2}{|c|}{45.45} & \multicolumn{2}{|c|}{46.10} \\
\hline Mean & \multicolumn{2}{|c|}{9.29} & \multicolumn{2}{|c|}{10.08} & \multicolumn{2}{|c|}{11.83} & \multicolumn{2}{|c|}{12.54} & \multicolumn{2}{|c|}{11.66} \\
\hline \multicolumn{11}{|l|}{ S.D. } \\
\hline F-test & \multicolumn{10}{|c|}{2.36} \\
\hline$P$ value & \multirow{2}{*}{\multicolumn{2}{|c|}{67.40}} & & & \multicolumn{2}{|c|}{0.465 N.S. } & & & \multirow{2}{*}{\multicolumn{2}{|c|}{66.85}} \\
\hline Weight (kg) & & & & & & & \multicolumn{2}{|c|}{67.50} & & \\
\hline Mean & & & & & & & & & & \\
\hline S.D. & & & & & & & & & & \\
\hline F -test & & & & & & & & & & \\
\hline$P$ value & & & & & 0.5 & J.S. & & & & \\
\hline Height & & & & & & & & & & \\
\hline Mean & & & & & & & & & & \\
\hline S.D. & & & & & & & & & & \\
\hline F -test & & & & & & & & & & \\
\hline$P$ value & & & & & 0.30 & J.S. & & & & \\
\hline ASA & No & $\%$ & No & $\%$ & No & $\%$ & No & $\%$ & No & $\%$ \\
\hline I & 16 & 80 & 17 & 85 & 16 & 80 & 16 & 80 & 16 & 80 \\
\hline II & 4 & 20 & 3 & 15 & 4 & 20 & 4 & 20 & 4 & 20 \\
\hline$X^{2}$ & & & & & & & & & & \\
\hline p & & & & & 0.99 & v.S. & & & & \\
\hline Duration of & & & & & & & & & & \\
\hline surgery (min) & & & & & & & & & & \\
\hline Mean S.D. & & & & & & & & & & \\
\hline F -test & & & & & & & & & & \\
\hline$P$ value & & & & & 0.6 & J.S. & & & & \\
\hline Type ofoperation & No & $\%$ & No & $\%$ & No & $\%$ & No & $\%$ & No & $\%$ \\
\hline Anal fissure & 1 & 5.0 & 3 & 15.0 & 3 & 15.0 & 3 & 15.0 & 3 & 15.0 \\
\hline appendicectomy & 1 & 5.0 & 2 & 10.0 & 3 & 15.0 & 2 & 10.0 & 2 & 10.0 \\
\hline Hernioplasty & 6 & 30.0 & 6 & 30.0 & 6 & 30.0 & 5 & 25.0 & 6 & 30.0 \\
\hline Hysterectomy & 3 & 15.0 & 2 & 10.0 & 2 & 10.0 & 2 & 10.0 & 1 & 5.0 \\
\hline Piles & 3 & 15.0 & 3 & 15.0 & 1 & 5.0 & 3 & 15.0 & 3 & 15.0 \\
\hline Pilonidal sinus & 2 & 10.0 & 1 & 5.0 & 1 & 5.0 & 1 & 5.0 & 1 & 5.0 \\
\hline Varicocele & 4 & 20.0 & 3 & 15.0 & 4 & 20.0 & 4 & 20.0 & 4 & 20.0 \\
\hline Total & 20 & 100.0 & 20 & 100.0 & 20 & 100 & 20 & 100.0 & 20 & 100.0 \\
\hline $\mathrm{X}^{2}$ & & & & & & & & & & \\
\hline $\mathbf{P}$ & & & & & 0.4 & J.S. & & & & \\
\hline
\end{tabular}




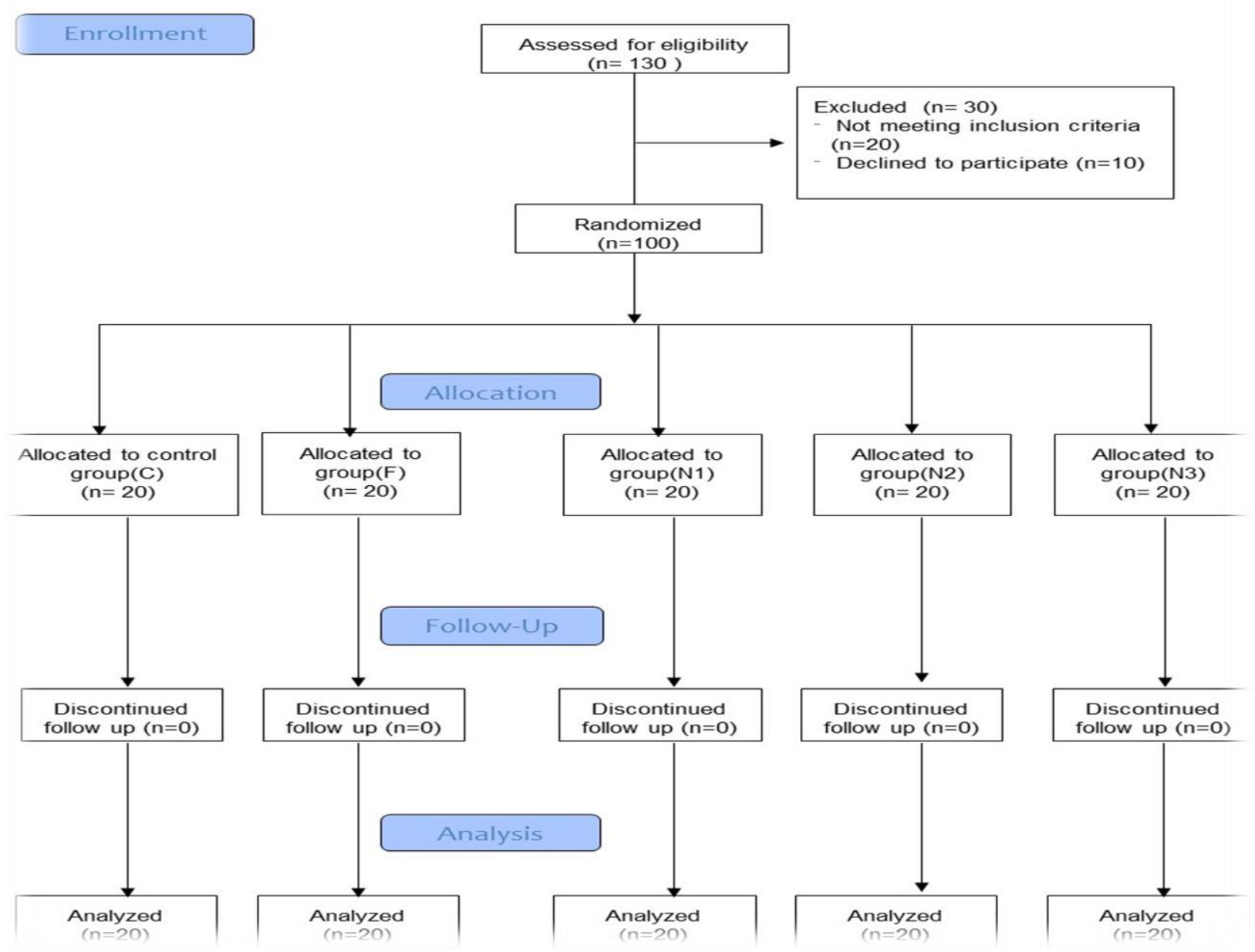

Fig (1) CONSORT flow diagram of the study

Table (2) Comparison between different studied groups regarding intra-operative side effects.

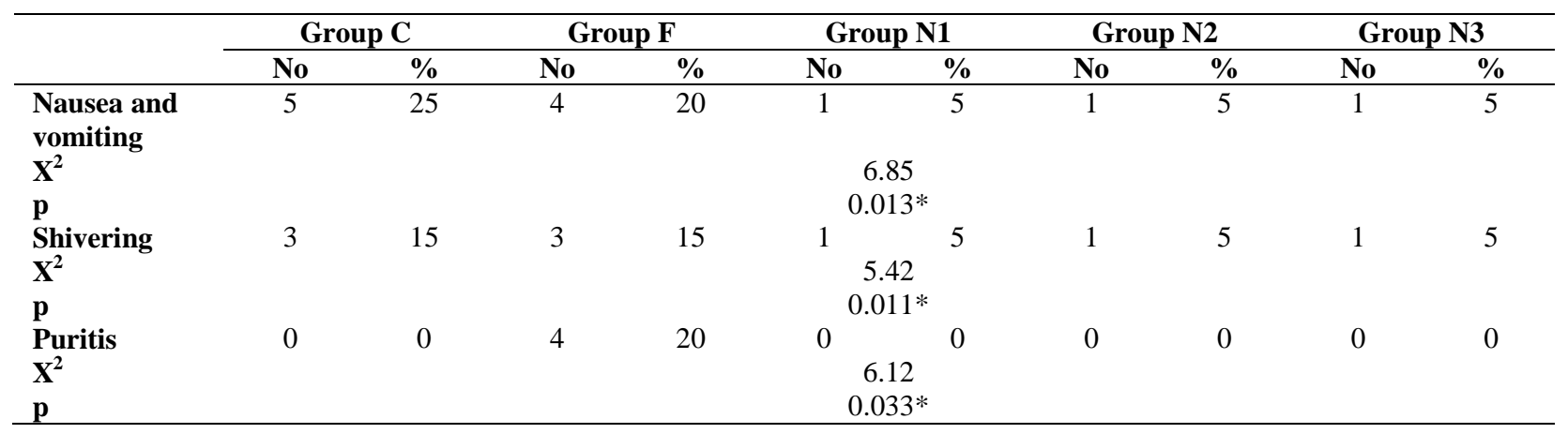

Table (3) Comparison between different studied groups regarding onset of sensory blockade (min), complete motor blockade (min) and highest level of sensory blockade (min).

\begin{tabular}{|c|c|c|c|c|c|}
\hline & Group C & Group F & Group N1 & Group N2 & Group N3 \\
\hline Onset of sensory blockade & 1.753 & 1.416 & 1.643 & 1.631 & 1.491 \\
\hline$(\min )$ & 0.103 & 0.081 & 0.120 & 0.105 & 0.076 \\
\hline \multicolumn{6}{|l|}{ Mean } \\
\hline S.D. & & & & & \\
\hline ANOVA & & & 6.02 & & \\
\hline$P$ value & & & $0.015 *$ & & \\
\hline
\end{tabular}


Table (3) Continue

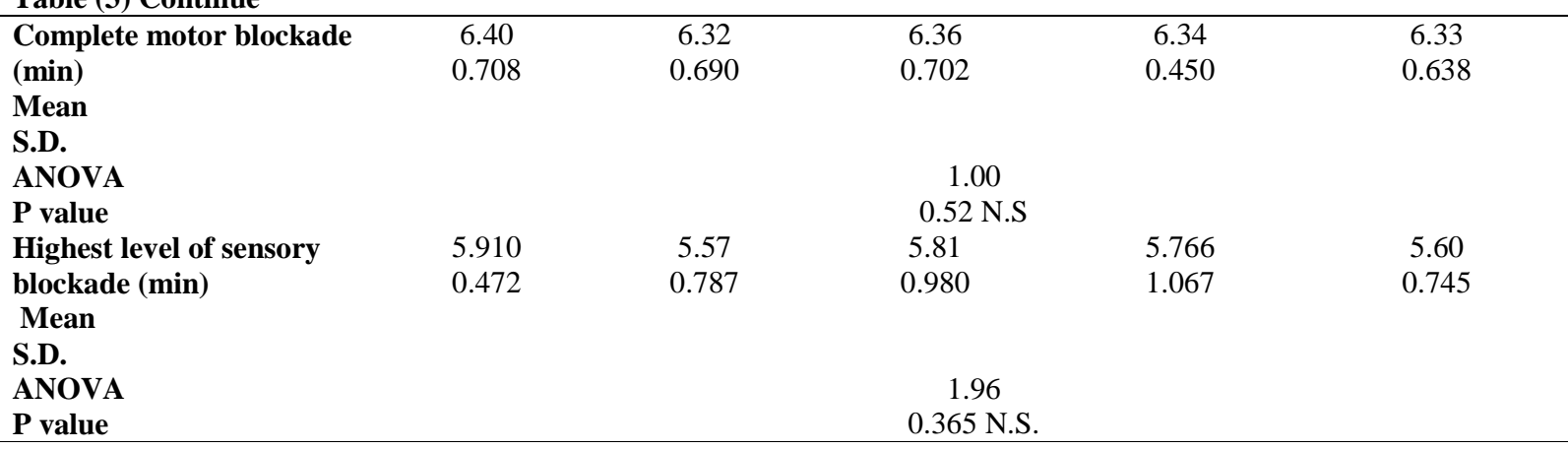

Table (4) Comparison between different studied groups regarding duration of sensory blockade (min) and duration of motor blockade (min).

\begin{tabular}{|c|c|c|c|c|c|}
\hline & Group C & Group F & Group N1 & Group N2 & Group N3 \\
\hline Duration of sensory & 118.070 & 151.977 & 134.156 & 140.984 & 158.251 \\
\hline blockade (min) & 4.316 & 3.124 & 3.718 & 4.059 & 3.908 \\
\hline $\begin{array}{l}\text { Mean } \\
\text { S.D. }\end{array}$ & & & & & \\
\hline ANOVA & & & 17.25 & & \\
\hline$P$ value & & & $0.002 *$ & & \\
\hline Duration of motor & 109.130 & 139.630 & 129.130 & 130.414 & 146.919 \\
\hline blockade (min) & 2.304 & 10.616 & 4.015 & 3.552 & 3.724 \\
\hline Mean & & & & & \\
\hline $\begin{array}{l}\text { S.D. } \\
\text { ANOVA } \\
\text { P value }\end{array}$ & & & $\begin{array}{c}14.21 \\
0.005^{*}\end{array}$ & & \\
\hline
\end{tabular}

Table (5) Comparison between different studied groups regarding pain score visual analogue scale (VAS).

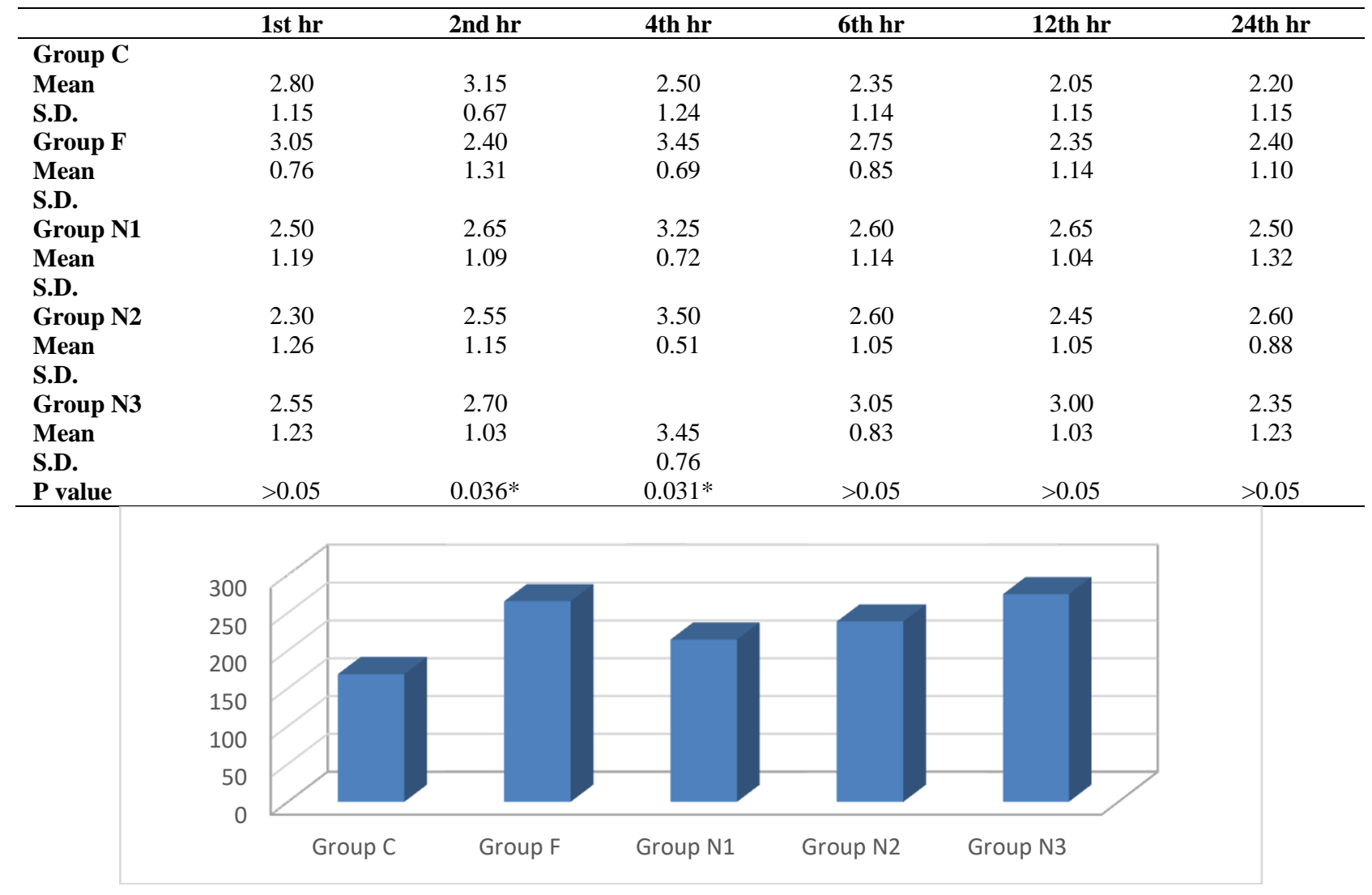

Fig (2) Comparison between different studied groups regarding the duration of effective analgesia 


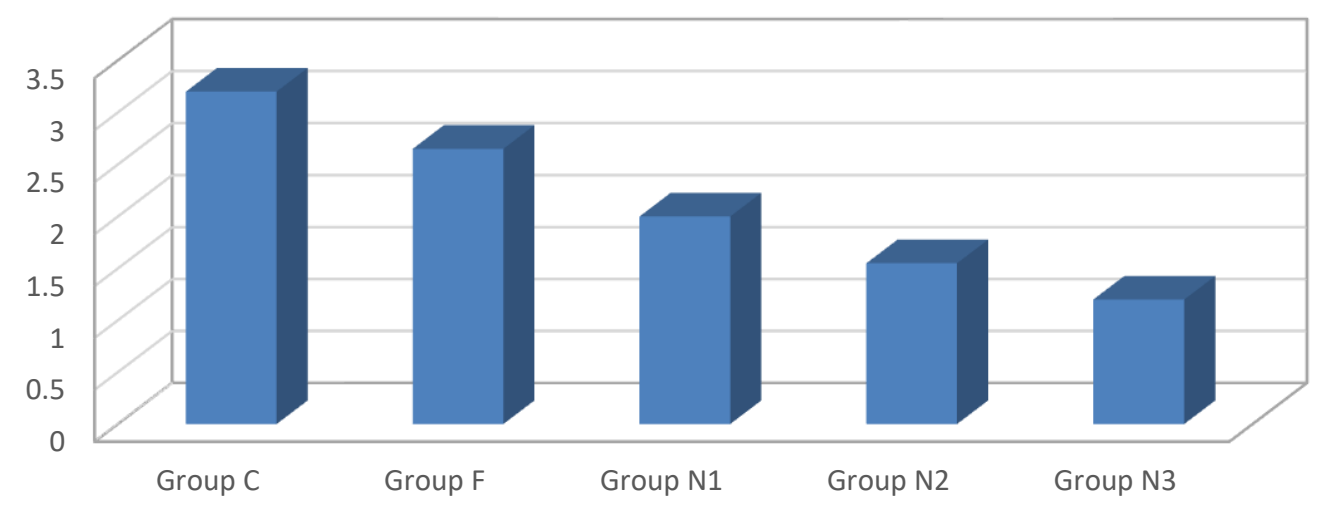

Fig (3) Comparison between different studied groups regarding total number of rescue analgesics required in 24 hours period.

\section{Discussion}

The blend of nearby anesthetics\& narcotics diminishes the portions of each medication with ensuing decrease in the occurrences of the related unfriendly impacts of each one, improves the nature of sedation, and will build the time of postoperative analgesia [5].

In the current examination there have been no significant varieties between the five gatherings' with respect to segment information. The examination between the five gatherings included BP, HR, RR and $\mathrm{SpO} 2$ and there have not been any fundamental qualification as intrathecal narcotics are synergistic with neighborhood sedatives and expand the tangible square without expanding the thoughtful square. Our outcomes are like Gomaa et al. who discovered no fundamental differentiation in hemodynamic parametersinside their examination groups [6].

In the momentum study, The rates of pruritis were fundamentally higher in fentanyl bunch than in nalbuphine bunches which were nil that is clarified by the counter pruritic impact of $\mu$ receptor enemies and control bunch likewise the examination was factually critical in the rate of retching and queasiness and shuddering which were higher in benchmark group and fentanyl bunch than nalbuphine gatherings.

The higher frequencies of pruritis and shuddering in fentanyl bunch that were recognized in present examination not distinguished inside the investigation by Vashishth et al. who looked at the outcomes of adding nalbuphine or fentanyl as a partner with bupivacaine for spinal sedation in patients booked for lower stomach and lower appendage medical procedures, and that they saw fentanyl is in a way that is better than nalbuphine regarding beginning of square and length of absense of pain with no impressive hemodynamic unsettling influences and unfriendly effects' and this could be clarified by the diverse fentanyl dosages that have been utilized in each investigation and distinctive patient gathering.
Fentanyl portion was $25 \mu \mathrm{g}$ in the our examination and was $10 \mu \mathrm{g}$ in the investigation done by Vashishth et al [7].

In the current examination, it was discovered that, as an adding to 15 milligram hyperbaric bupivacaine in subarachnoid block, fentanyl $(25 \mu \mathrm{g})$ was better than nalbuphine gatherings and control bunch in spreading beginning of tangible bar since fentanyl might be exceptionally lipid dissolvable. Be that as it may, nalbuphine $(0.8 \mathrm{mg})$ was better than fentanyl and control bunches in upgrading the time of postoperative complete and successful absense of pain and this corresponds with concentrates by Tiwari AK et al., Mostafa et al. who announced that giving patients bupivacaine alone had huge high agony scores more sooner than patients who got nalbuphine-bupivacaine mixes as surveyed by VAS additionally these examinations revealed that nalbuphine improve time of absense of pain with decreased VAS torment score $[8,9]$.

Just as an investigation led by Culebras et al. additionally revealed that intrathecal nalbuphine 0.8 $1.6 \mathrm{mg}$ had improvement as respect the nature of intraoperative absense of pain during cesarean conveyances with great instinctive absense of pain, Culebras et al. looked at the viability for postoperative relief from discomfort and unfriendly impacts of three unique dosages $(0.2,0.8$, and 1.6 $\mathrm{mg}$ ) of intrathecal nalbuphine with $0.2 \mathrm{mg}$ of intrathecal morphine for instances of cesarean conveyances. Among the nalbuphine-treated gatherings, $0.8 \mathrm{mg}$ portion gave the longest lengths of both complete and successful postoperative absense of pain. Expanding the nalbuphine portion to $1.6 \mathrm{mg}$ didn't have further pain relieving impact which might be credited to nalbuphine roof impact above $0.8 \mathrm{mg}$ portion for example an expansion in nalbuphine portion expands the pain relieving impact till a particular point as over this point there is no improvement of absense of pain with expanding the portion. Neither pruritis nor PONV was seen with 0.2 
$\mathrm{mg}$ or $0.8 \mathrm{mg}$ nalbuphine. The creators presumed that intrathecal $0.8 \mathrm{mg}$ nalbuphine was viewed as the best portion that delivers a comparable pain relieving impact as $0.2 \mathrm{mg}$ morphine with minimal unfavorable effects [10].

In current examination, the 2 portion relapse of tangible square and time of engine bar were more upgraded with adding nalbuphine $(0.8 \mathrm{mg})$ to intrathecal bupivacaine than option of fentanyl (25 $\mu \mathrm{g})$ to intrathecal bupivacaine however measurably inconsequential, while in the gathering $\mathrm{C}$ there was a factual critical diminishing than different gatherings which associates with that of Gupta et al. study who contrasted 2 milligram nalbuphine and 25- $\mu$ g fentanyl intrathecal joined with 17.5 milligram hyperbaric bupivacaine in subarachnoid block for muscular medical procedure. They saw upgraded time of both engine and tangible square, more postoperative pain relieving impact, and less results particularly in patients who got nalbuphine [11].

In current examination the qualification in mean length of viable absense of pain was factually significant in the gatherings in correlation with each other, the pinnacle was in Group N3 followed by Group F at that point bunch N2, N1 lastly bunch C. Our outcomes were similar to Jyothi et al. who directed an examination in 100 patients partitioned into four gatherings: A, B, C, and D given $0.5 \mathrm{ml} \mathrm{NS}$ and $0.8,1.6$, and $2.5 \mathrm{mg}$ nalbuphine, separately, and settled that nalbuphine significantly drawn out span for first solicitation of absense of pain when contrasted with control bunch conjointly our outcomes are much the same as to that of Srivastava et al. study who utilized intrathecal fentanyl with weighty lidocaine and saw that fentanyl not just expanded the beginning and increased the length of tactile square however conjointly delayed the postoperative pain relieving period while not influencing the recuperation of engine block [12, 13].

In our examination patients who got intrathecal nalbuphine in gatherings N1, N2 and N3 required significantly lesser assortment of salvage analgesics than Group $\mathrm{C}$ and $\mathrm{F}$ also, the patients in fentanyl bunch required extensively lesser absense of pain than the patients in Group $\mathrm{C}$, these outcomes resemble to that got by Naaz et al. what's more, Mostafa et al. conjointly a planned report directed by Moustafa and Saleh have detailed that adding 1-mg nalbuphine to $0.2-\mathrm{mg}$ morphine all through subarachnoid barricade alienates the morphineprompted unfriendly effects like sickness spewing and pruritis with none impact on the time of postoperative absense of pain, absense of pain quality, or the level of postoperative salvage pain relieving request dose $[9,14,15]$.

Nalbuphine $0.8 \mathrm{mg}$ is more in a way that is better than fentanyl in improving the time of postoperative complete and compelling absense of pain, lessening the need of postoperative salvage analgesics and has better highlights, for example, against pruritic, lesser shuddering, sickness and retching so nalbuphine 0.8 $\mathrm{mg}$ is protected, significant and the best among the gatherings. The outcomes in this examination are like Raghuraman who contemplated the intrathecal nalbuphine's belongings in the written works and saw that nalbuphine when joined with the neighborhood sedation for subarachnoid block improve the quality and upgrade the time of postoperative absense of pain with against shuddering and hostile to pruritic impact, with diminished occurrence of sickness retching [16].

\section{Conclusion}

Nalbuphine $0.8 \mathrm{mg}$ is more better than fentanyl in enhancing the period of postoperative complete and effective analgesia, diminishing the need of postoperative rescue analgesics and has better features such as anti-pruritic, lesser shivering, nausea and vomiting so nalbuphine $0.8 \mathrm{mg}$ is safe, valuable and the best among the groups.

\section{References}

[1] P.Ahluwalia, A.Ahluwalia, R.Varshney. Prospective Randomized Double-Blind Study to Evaluate the Effects of IntrathecalNalbuphine in Patients of Lower Abdominal Surgeries under Spinal Anaesthesia. Inter J Scie Study, Vol.3(3), PP.19-23, 2015.

[2] C.A.Wong, B.M.Scavone, J.P.Slavenas. Efficacy and side effect profile of varying doses of intrathecal fentanyl added to bupivacaine for labor analgesia. Int $\mathrm{J}$ ObstetAnesth, Vol.13, PP.19-24, 2004.

[3] R.Seewal, D.Shende, L.Kashyap. Effect of addition of various doses of fentanyl intrathecally to $0.5 \%$ hyperbaric bupivacaine on perioperative analgesia and subarachnoid-block characteristics in lower abdominal surgery: A dose-response study. RegAnesth Pain Med, Vol.32, PP.20-6, 2007.

[4] S.Kumaresan, A.A.Raj. Intrathecalnalbuphine as an adjuvant to spinal anaesthesia: What is most optimum dose? Int J Sci Stud, Vol.5, PP.57-60, 2017.

[5] S.Verstraete, Van de M.Velde. Post-cesarean section analgesia. ActaAnaesthesiolBelg, Vol. 63, PP.147-167,2012.

[6] H.M. Gomaa, N.N.Mohamed, H.A.Zoheir. comparison between post-operative analgesia after intrathecalnalbuphine with bupivacaine and intrathecal fentanyl with bupivacaine after caesarean section. Egypt J Anaesth, Vol.30, PP.405-10, 2014.

[7] T.Vashishth, G.Sharma, S.Garg. Comparative study of Nalbuphine and Fentanyl with Bupivacaine in spinal anaesthesia for lower abdominal and lower limb surgeries. Nat J Med Dent Res, Vol.4, PP.93-100, 2016.

[8] A.K.Tiwari, G.S. omar, J.Agrawal. Intrathecal bupivacaine in comparision with a combination of 
nalbuphine and bupivacaine for subarachnoid block: A randomized prospective double blind clinical study. Am J Ther, Vol.20, PP.592-5, 2013.

[9] M.G.Mostafa, M.F.Mohamad, W.S. Farrag.Which has greater analgesic effect; Intrathecalnalbuphine or intrathecal tramadol. J Am Sci, Vol.7, PP.4804, 2011.

[10] X.Culebras, G.Gaggero, J.Zatloukal. Advantages of intrathecalnalbuphine compared with intrathecal morphine after cesarean delivery: an evaluation of postoperative analgesia and adverse effects. AnesthAnalg, Vol.91, PP.601605,2000 .

[11] K.Gupta, B.Rastogi, P.K.Gupta, Singh . Intrathecalnalbuphine versus intrathecal fentanyl as adjuvant to $0.5 \%$ hyperbaric bupivacaine for orthopedic surgery of lower limbs under subarachnoid block: A comparative evaluation. Indian J Pain, Vol. 30, PP.90-95 , 2016.

[12] B.Jyothi, S.Gowda, S.I.Shaikh. A comparison of analgesic effect of different doses of intrathecalnalbuphine hydrochloride with bupivacaine and bupivacaine alone for lower abdominal and orthopedic surgeries. Indian $\mathbf{J}$ Pain, Vol.28, PP.18-23,2014.

[13] U.Srivastava, A.Kumar, S.Saxena. Spinal anaesthesia with lignocaine and fentanyl. Ind J Anaesthesiol, Vol.48, PP.121-123,2004.

[14] S.Naaz, U.Shukla, S.Srivastava. comparative study of analgesic effect of intrathecalnalbuphine and fentanyl as adjuvant in lower limb orthopaedic surgery. J ClinDiagn. Res, Vol.11, PP.UC25-8,2017.

[15] M.A.Moustafa, R.S.Saleh. Nalbuphine added to intrathecal morphine in total knee arthroplasty; effect on postoperative analgesic requirements and morphine related side effects. Alexandria $\mathrm{J}$ Med, Vol.48, PP.175-178, 2012.

[16] M.S.Raghuraman. Intrathecalnalbuphine, will it gain wider acceptance? A narrative review. Egypt J Anesth, Vol. 33, PP.289-293, 2017. 